PASTORINI, L.H.; BACARIN, M.A.; TREVIZOL, F.C.; BERVALD, C.M.P.; FERNANDES, H.S. Produção e teor de carboidratos não estruturais em tubérculos de batata obtidos em duas épocas de plantio ${ }^{1}$. Horticultura Brasileira, Brasília, v. 21, n. 4, p. 660-665, outubro/dezembro 2003.

\title{
Produção e teor de carboidratos não estruturais em tubérculos de batata obtidos em duas épocas de plantio ${ }^{1}$
}

\author{
Lindamir H. Pastorini'²; Marcos Antonio Bacarin ${ }^{3}$; Fabio Cristiano Trevizol ${ }^{4}$; Clauber Mateus P. Bervald ${ }^{4}$; \\ Heloisa S. Fernandes 5 \\ ${ }^{2}$ URI, Universidade Regional Integrada do Alto Uruguai e das Missões, Av. Assis Brasil, 709, 98400-000 Frederico Westphalen-RS; ${ }^{3}$ \\ UFPel, Depto. Botânica, C. Postal 354, 96010-960 Pelotas-RS; ${ }^{4}$ Bolsista de Iniciação Científica-PIBIC/UFPel, Depto. Botânica C. Postal \\ 354, 96010-960 Pelotas-RS; ${ }^{5}$ Faculdade de Agronomia Eliseu Maciel, C. Postal 354, 96010-960 Pelotas-RS; E-mail: lindamir@fw.uri.br
}

\begin{abstract}
RESUMO
Tubérculos de batata cv. Atlantic e Pérola, obtidos do cultivo de outono (53; 68 e 100 dias após o plantio - DAP) e primavera $(70 ; 78$ e 99 DAP) foram levados ao laboratório e classificados quanto ao diâmetro (<30 mm, 30-50 mm e >50mm), contados e determinada individualmente a massa fresca. Em seguida, coletaram-se amostras para análise dos teores de amido, carboidratos solúveis totais, açúcares redutores e sacarose. Durante o cultivo de outono, a cultivar Atlantic apresentou maior massa fresca dos tubérculos ao final do ciclo e a cv. Pérola apresentou maior número de tubérculos em todas as colheitas. No cultivo da primavera a cv. Pérola apresentou maior massa fresca média dos tubérculos, sendo que em ambas cultivares, observou-se redução da produtividade ao final do ciclo, talvez em resposta ao estresse hídrico verificado no período. Considerando o fator cultivar, observa-se que o teor de amido foi significativamente maior nos tubérculos da cv. Pérola aos 53 e 100 DAP do cultivo de outono, enquanto a cv. Atlantic apresentou valores significativamente maiores de carboidratos solúveis totais aos 53 DAP. Houve redução nos teores de açúcares redutores, em ambas cultivares, ao final do cultivo de outono, o que também foi verificado para os teores de sacarose. Os teores de amido e carboidratos solúveis totais reduziram, em ambas cultivares ao longo do ciclo de primavera, sendo que não houve diferença entre as cultivares em relação aos teores de açúcares redutores e sacarose ao final do cultivo de primavera.
\end{abstract}

Palavras-chave: Solanum tuberosum, amido, açúcares redutores, sacarose.

\begin{abstract}
Production and non-structural carbohydrates content in potato tubers obtained in two planting times

Potato tubers, cv. Atlantic and Pérola, harvested in autumn (53; 68 and 100 days after the planting - DAP) and spring cultivation $(70,78$ and 99 DAP) were classified in relation to the diameter $(<30$ $\mathrm{mm}, 30-50 \mathrm{~mm}$ and $>50 \mathrm{~mm}$ ), counted and the fresh mass determined individually. Samples were collected and analyzed for the content of starch, total soluble carbohydrates, reducer sugars and sucrose. During autumn cultivation, the tubers of $\mathrm{cv}$. Atlantic presented higher fresh mass at the end of the cycle and the cv. Pérola presented greater number of tubers in all the collections. In the spring cultivation the cv. Pérola presented higher average fresh mass in tubers, and in both cultivars was observed a reduction in the productivity at the end of the cycle, perhaps as a response to water stress verified in the period. Content of starch was significantly larger in the cv. Pérola at 53 and $100 \mathrm{DAP}$ of the autumn cultivation, while the cv. Atlantic presented significantly larger values of total soluble carbohydrates at 53 DAP. Reduction in reducing sugars and sucrose content was observed in both cultivars at the end of the autumn cultivation. The content of starch and total soluble carbohydrates decreased, in both cultivars along the spring cycle. No differences between cultivars in relation to reducing sugars and sucrose content were observed at the end of the spring cultivation.
\end{abstract}

Keywords: Solanum tuberosum, starch, reducers sugars, sucrose.

\section{(Recebido para publicação em 30 de outubro de 2002 e aceito em 4 de julho de 2003)}

\begin{abstract}
A batata (Solanum tuberosum L.) é nível mundial, em ordem de importância econômica, a quarta cultura agrícola, sendo plantada em pelo menos 125 países e consumida por mais de um bilhão de pessoas em todo o mundo (Freire, 1998).

No Rio Grande do Sul cultiva-se anualmente cerca de 50.000 ha e, apesar das boas condições edafoclimáticas, a produtividade média está em torno de 10 t ha $^{-1}$, estando abaixo da média nacional de $18 \mathrm{t} \mathrm{ha}^{-1}$ (FNT, 2001). Atualmen-
\end{abstract}

te, as principais cultivares plantadas no Brasil são Achat, Atlantic, Asterix, Baronesa, Bintje e Monalisa (Melo, 1999). Para a agroindústria de batata frita vem sendo utilizada a cultivar norte-americana Atlantic (Filgueira, 2000). Pérola foi recentemente lançada pela Embrapa para a indústria de batata palha (Pereira et al, 2000).

Os fatores de importância comercial dos tubérculos, tanto para o processamento industrial como para o consumo in natura, são o teor, qualida- de do amido e a composição bioquímica, principalmente, em termos de açúcares redutores. A composição da matéria seca pode variar de acordo com a cultivar, condições de cultivo e grau de maturidade dos tubérculos, sendo que os compostos químicos não são distribuídos homogeneamente no tubérculo (van Es \& Hartmans, 1987).

Dentre os vários tipos de processamento destacam-se a batata frita ou "chips", batata frita congelada, batata frita desidratada e farinha de batata

1 Parte integrante da tese de doutorado do primeiro autor, realizada na Faculdade de Agronomia Eliseu Maciel da UFPel. 
(Pereira, 1987; Silva, 1991; Davies \& Mackay, 1994). A cor é o fator mais importante no julgamento da qualidade do "chips" pelo consumidor, sendo que o escurecimento excessivo indica baixa qualidade, por estar associado ao "chips" queimado, além de apresentarem gosto amargo (Pereira \& Costa, 1997). O escurecimento da batata está associado ao alto teor de açúcares redutores que reagem com os aminoácidos livres, fenômeno conhecido como efeito Maillard (Shallenberg et al., 1959; Talburt et al., 1975).

Em tubérculos de batata, o amido é o principal carboidrato armazenado, correspondendo de 60 a $80 \%$ da matéria seca do órgão (Pereira, 1987; van Es \& Hartmans, 1987; Kobmann et al., 1995). Os grãos de amido são formados já nos estádios iniciais da tuberização, aumentando o seu conteúdo durante o crescimento do tubérculo (van Es \& Hartmans, 1987).

A sacarose é o principal carboidrato translocado pelas plantas, sendo também reconhecida como tendo uma importante função na regulação metabólica, sinalizando processos na expressão de genes e na determinação do desenvolvimento e diferenciação nas plantas (Salisbury \& Ross, 1992; Chourey et al., 1995).

A quebra enzimática da sacarose em órgãos drenos pode ser de grande importância para mecanismo da conversão em amido, quer transitoriamente ou como depósito de amido. A essência de toda reação é o acoplamento da sacarose sintase com clivagem da UDP-glicose dependente de pirofosfato (PPi) para produzir glicose-1-fosfato, catalisando o primeiro passo da biossintese de amido nestes órgãos (Akazawa et al., 1995; Guerin \& Carbonero, 1997).

A baixa taxa de síntese de sacarose pode causar aumento no nível de trioses fosfato e reduzir Pi no citoplasma, e como resultado o carbono pode ser desviado para a síntese de amido. A taxa de formação de sacarose pode, desse modo, regular indiretamente a taxa de formação de amido (Huber \& Israel, 1982).

O presente trabalho teve por objetivo quantificar os teores dos carboidratos não estruturais e a produção de tubérculos de batata obtidos em diferentes épocas de plantio.

\section{MATERIAL E MÉTODOS}

O experimento, utilizando-se cultivares de batata Atlantic e Pérola, foi conduzido no campo experimental da Embrapa Clima Temperado no município de Pelotas, RS. Realizou-se os plantios de outono (13/03/2000) e de primavera $(05 / 09 / 2000)$.

Em cada plantio foram realizadas três coletas que consistiam na retirada de todos os tubérculos de 20 plantas de cada cultivar. Imediatamente após a colheita, os tubérculos foram transferidos para o laboratório onde foram classificados quanto ao diâmetro em três classes (<30 mm; 30-50 $\mathrm{mm} \mathrm{e}>50 \mathrm{~mm})$, contados e pesados individualmente. Após a classificação dos tubérculos, coletaram-se amostras para análises químicas, de aproximadamente $1 \mathrm{~g}$ da região central de quatro tubérculos por classe de tamanho. Tais amostras foram armazenadas em etanol $80 \%$ e mantidas sob refrigeração até o processamento.

Para a determinação dos teores de amido, carboidratos solúveis totais, açúcares redutores e sacarose, as amostras previamente coletadas foram maceradas e centrifugadas para a obtenção de extrato alcoólico, o qual foi evaporado e adicionado água destilada obtendo-se extrato aquoso, a partir do qual determinou-se os teores de compostos solúveis. Com o resíduo da centrifugação realizou-se a hidrólise ácida para a determinação dos teores de amido segundo o método descrito por McCready et al. (1950). Os teores de carboidratos solúveis totais foram determinados através das reações com antrona (Clegg, 1956) e os açúcares redutores pelo método de Somogy-Nelson (Nelson, 1944; Hodge \& Hofreiter, 1962). A sacarose foi determinada através da reação com antrona fria, após adição de $\mathrm{KOH}$ quente (Passos, 1996).

Para cada época de plantio foi utilizado o delineamento experimental inteiramente casualizado, em esquema fatorial $2 \times 3$, sendo duas cultivares e três classes de diâmetro (<30, de 30-50 e >50 mm), com quatro repetições, por tratamento.

Os resultados obtidos dos teores de açúcares foram submetidos à análise de variância e comparados pelo teste de
Tukey, analisando-se os fatores principais e os desdobramentos dos graus de liberdade para as interações significativas.

\section{RESULTADOS E DISCUSSÃO}

Ao final do cultivo de outono, considerando as 20 plantas coletadas de cada cultivar, foi verificado que as plantas da cv. Atlantic apresentaram menor número total de tubérculos (100) e maior massa fresca total $(7,62 \mathrm{~kg})$, sendo que as plantas da cv. Pérola obtiveram 116 tubérculos e $7,07 \mathrm{~kg}$ de massa fresca. No cultivo de primavera, ao final do ciclo, os tubérculos da cv. Perola e Atlantic apresentaram 1,93 kg de massa fresca. A redução da produtividade no final do ciclo, possivelmente foi devido a falta de chuva no mês de dezembro. Neste período as temperaturas máximas também foram altas, acima da considerada normal para o período, fazendo com que o ciclo de crescimento e desenvolvimento das plantas fosse reduzido, acarretando, portanto queda na produtividade.

Considerando a distribuição dos tubérculos dentro dos tamanhos $(<30,30$ 50 e $>50 \mathrm{~mm}$ ), verificou-se que no cultivo de outono, aos 53 DAP, em ambas cultivares, não foram observados tubérculos com diâmetro maior do que $50 \mathrm{~mm}$, e aos 100 DAP não foram encontrados tubérculos com diâmetro inferior a 30 $\mathrm{mm}$. No cultivo de primavera, aos 70 DAP, a cultivar Pérola não apresentou tubérculos com diâmetro acima de 50 mm, enquanto que aos 99 DAP, ambas cultivares não apresentaram tubérculos inferiores a $30 \mathrm{~mm}$ de diâmetro.

A pluviosidade foi o fator que mais influenciou a queda da produtividade no final do cultivo de primavera. Segundo Passos et al. (1984), a época de maior consumo de água ocorre normalmente quando a planta atinge o máximo de desenvolvimento vegetativo e o máximo de crescimento dos tubérculos, ou seja, 60 dias após o plantio até a maturação. Essa redução da massa fresca e diâmetro dos tubérculos observados tanto na cv. Atlantic quanto na cv. Pérola talvez tenha ocorrido devido ao estresse hídrico entre a segunda (76 DAP) e a última coleta (99 DAP). Durante este período, foram 19 dias sem 
Tabela 1. Teor de amido ( $\mathrm{mg}$ amido $\mathrm{g}^{-1}$ massa fresca) e de carboidratos solúveis ( $\mathrm{mg}$ glicose $\mathrm{g}^{-1}$ ) em tubérculos de batata em função dos dias após o plantio (DAP), durante o cultivo de outono e primavera. Pelotas, EMbrapa Clima Temperado, 2000.

\begin{tabular}{|c|c|c|c|c|c|c|c|}
\hline \multirow{4}{*}{ Cultivar } & \multicolumn{7}{|c|}{ Cultivo de outono } \\
\hline & \multirow{3}{*}{$\begin{array}{l}\phi \text { tubérculos } \\
(\mathrm{mm})\end{array}$} & \multicolumn{6}{|c|}{ DAP } \\
\hline & & \multicolumn{2}{|c|}{53} & \multicolumn{2}{|c|}{68} & \multicolumn{2}{|c|}{100} \\
\hline & & Amido & $\begin{array}{l}\text { Carboidra- } \\
\text { tos solúveis } \\
\text { totais }\end{array}$ & Amido & $\begin{array}{c}\text { Carboidra- } \\
\text { tos solúveis } \\
\text { totais }\end{array}$ & Amido & $\begin{array}{l}\text { Carboidra- } \\
\text { tos solúveis } \\
\text { totais }\end{array}$ \\
\hline \multirow{4}{*}{ Pérola } & $<30$ & $55,70 \mathrm{~b} \alpha\left(^{*}\right)$ & 4,01 a $\beta\left(^{*}\right)$ & $106,38 \mathrm{a} \alpha$ & $12,33 \mathrm{a} \alpha$ & - & - \\
\hline & $30-50$ & $70,46 \mathrm{a} \alpha$ & 6,27 a $\alpha$ & $100,95 \mathrm{a} \alpha$ & $3,31 \mathrm{~b} \alpha$ & 72,75 a $\alpha$ & $1,62 \mathrm{~b} \alpha$ \\
\hline & $>50$ & - & - & $84,91 \mathrm{a} \alpha$ & $2,12 \mathrm{~b} \alpha$ & $45,13 \mathrm{~b} \beta$ & $2,51 \mathrm{a} \alpha$ \\
\hline & Média & $63,08 \mathrm{~A}$ & $5,14 \mathrm{~B}$ & $98,24 \mathrm{~A}$ & $5,92 \mathrm{~A}$ & $58,94 \mathrm{~A}$ & $2,06 \mathrm{~A}$ \\
\hline \multirow{8}{*}{ Atlantic } & $<30$ & $45,76 \mathrm{a} \alpha$ & $10,69 \mathrm{a} \alpha$ & $98,82 \mathrm{a} \alpha$ & $9,55 \mathrm{a} \beta$ & - & - \\
\hline & $30-50$ & $33,63 \mathrm{~b} \beta$ & $5,86 \mathrm{~b} \alpha$ & $98,81 \mathrm{a} \alpha$ & $1,42 \mathrm{~b} \beta$ & $56,30 \mathrm{a} \beta$ & $1,60 \mathrm{a} \alpha$ \\
\hline & $>50$ & - & - & 97,09 a $\alpha$ & $1,57 \mathrm{~b} \beta$ & $52,34 \mathrm{a} \alpha$ & $1,55 \mathrm{a} \alpha$ \\
\hline & Média & $39,69 \mathrm{~B}$ & $8,27 \mathrm{~A}$ & $97,41 \mathrm{~A}$ & $4,18 \mathrm{~B}$ & $54,32 \mathrm{~B}$ & $1,58 \mathrm{~B}$ \\
\hline & \multicolumn{7}{|c|}{ Cultivo de primavera } \\
\hline & & \multicolumn{6}{|c|}{ DAP } \\
\hline & & \multicolumn{2}{|r|}{70} & \multicolumn{2}{|c|}{76} & \multicolumn{2}{|c|}{99} \\
\hline & & Amido & $\begin{array}{l}\text { Carboidra- } \\
\text { tos solúveis } \\
\text { totais }\end{array}$ & Amido & $\begin{array}{l}\text { Carboidra- } \\
\text { tos solúveis } \\
\text { totais }\end{array}$ & Amido & $\begin{array}{l}\text { Carboidra- } \\
\text { tos solúveis } \\
\text { totais }\end{array}$ \\
\hline \multirow{4}{*}{ Pérola } & $<30$ & $157,41 \mathrm{a} \alpha$ & $1,91 \mathrm{a} \alpha$ & $101,18 \mathrm{~b} \alpha$ & $2,37 \mathrm{a} \alpha$ & - & - \\
\hline & $30-50$ & $179,43 \mathrm{a} \alpha$ & $2,08 \mathrm{a} \alpha$ & 179,08 a $\alpha$ & 2,26 a $\alpha$ & $101,00 \mathrm{a} \alpha$ & 1,78 a $\alpha$ \\
\hline & $>50$ & - & & $129,17 \mathrm{ab} \alpha$ & $2,02 \mathrm{a} \alpha$ & 98,15 a $\alpha$ & $1,81 \mathrm{a} \alpha$ \\
\hline & Média & $168,42 \mathrm{~A}$ & $1,99 \mathrm{~A}$ & $136,48 \mathrm{~A}$ & $2,21 \mathrm{~A}$ & $99,57 \mathrm{~A}$ & $1,79 \mathrm{~A}$ \\
\hline \multirow{4}{*}{ Atlantic } & $<30$ & $126,47 \mathrm{a \alpha}$ & $1,57 \mathrm{a} \alpha$ & 172,86 a $\alpha$ & $2,12 \mathrm{a} \alpha$ & - & - \\
\hline & $30-50$ & $159,05 \mathrm{a} \alpha$ & $2,46 \mathrm{a} \alpha$ & 156,93 a $\alpha$ & $1,40 \mathrm{a} \alpha$ & 111,43 a $\alpha$ & 2,36 a $\alpha$ \\
\hline & $>50$ & $180,02 \mathrm{a \alpha}$ & $2,15 \mathrm{a} \alpha$ & 130,14 a $\alpha$ & $1,32 \mathrm{a} \alpha$ & $122,03 \mathrm{a} \alpha$ & $0,98 b \alpha$ \\
\hline & Média & $155,18 \mathrm{~A}$ & $2,06 \mathrm{~A}$ & $153,31 \mathrm{~A}$ & $1,61 \mathrm{~B}$ & $116,73 \mathrm{~A}$ & $1,67 \mathrm{~A}$ \\
\hline
\end{tabular}

(*) Médias seguidas por letras iguais não diferem entre si pelo teste de Tukey (5\%); letras minúsculas dentro da mesma cultivar (comparação entre tamanhos), letras maiúsculas para médias entre cultivares, letras gregas para comparação entre cultivares considerando o mesmo diâmetro e a mesma época.

chuvas, sendo que no mês de dezembro até o dia da última coleta não houve precipitação. Portanto, o estresse hídrico no período fez com que o ciclo de crescimento e desenvolvimento das plantas fosse reduzido, acarretando queda na produtividade. A redução da massa fresca e do tamanho dos tubérculos de batata devido ao estresse hídrico também é relatado por Melo (1999).

A redução do número de tubérculos ao final do ciclo em comparação com as coletas anteriores observada, em ambas cultivares e ciclos de cultivo, pode também estar relacionada à competição pelo limitado suprimento de assimilados (Milthorpe \& Moorby, 1966;
Beukema \& Zaag, 1990), já que no final do ciclo as plantas entram em senescência. Tal fato pode ser observado durante o cultivo de primavera, onde é mais acentuada a redução no número de tubérculos coletados.

Analisando o fator principal cultivar, no cultivo de outono, observa-se que o teor de amido (Tabela 1), foi significativamente maior na cultivar Pérola aos 53 e 100 DAP, entretanto não houve diferença entre as cultivares durante a segunda coleta. Considerando a comparação dentro de cada cultivar, observouse aos 53 DAP que os tubérculos de diâmetro entre 30 e $50 \mathrm{~mm}$ da cultivar Pérola apresentaram maior teor de amido, enquanto que para a cultivar Atlantic tal fato ocorreu nos tubérculos menores de $30 \mathrm{~mm}$. Na última coleta os tubérculos da cultivar Atlantic não apresentaram diferenças estatística $(p<0,05)$ porém diferenças foram observadas para os tubérculos da Pérola, de maneira que os teores de amido foram maiores nos tubérculos de tamanho entre 30 e 50 $\mathrm{mm}$. Para ambas as cultivares observouse que os teores de amido foram crescentes até os 68 DAP e reduziram ao final do ciclo (Tabela 1).

Durante o cultivo de primavera, o teor de amido nos tubérculos de batata (Tabela 1), não foi significativamente diferente entre as cultivares, em nenhu- 
Tabela 2. Teor de açúcares redutores ( $\mathrm{mg}$ glicose $\mathrm{g}^{-1}$ massa fresca) e de sacarose ( $\mathrm{mg}$ sacarose $\mathrm{g}^{-1}$ massa fresca) em tubérculos de batata em função dos dias após o plantio (DAP), durante o cultivo de outono e primavera. Pelotas, Embrapa Clima Temperado, 2000.

\begin{tabular}{|c|c|c|c|c|c|c|c|}
\hline \multirow{4}{*}{ Cultivar } & \multicolumn{7}{|c|}{ Cultivo de outono } \\
\hline & \multirow{3}{*}{$\begin{array}{l}\phi \text { tubérculos } \\
(\mathrm{mm})\end{array}$} & \multicolumn{6}{|c|}{ DAP } \\
\hline & & \multicolumn{2}{|c|}{53} & \multicolumn{2}{|c|}{68} & \multicolumn{2}{|c|}{100} \\
\hline & & $\begin{array}{l}\text { Açúcares } \\
\text { redutores }\end{array}$ & Sacarose & $\begin{array}{l}\text { Açúcares } \\
\text { redutores }\end{array}$ & Sacarose & $\begin{array}{l}\text { Açúcares } \\
\text { redutores }\end{array}$ & Sacarose \\
\hline \multirow{4}{*}{ Pérola } & $<30$ & $0,82 \mathrm{a} \alpha\left(^{*}\right)$ & $2,29 a \alpha \quad\left(^{*}\right)$ & $2,21 \mathrm{a} \beta$ & 1,15 a $\beta$ & - & - \\
\hline & $30-50$ & $0,68 \mathrm{a \alpha}$ & $4,16 \mathrm{a} \alpha$ & $2,20 \mathrm{~b} \alpha$ & 2,51 a $\alpha$ & $0,34 \mathrm{a} \beta$ & $1,28 \mathrm{a} \alpha$ \\
\hline & $>50$ & - & - & $0,13 \mathrm{~b} \alpha$ & 1,87 a $\alpha$ & $0,53 \mathrm{a} \alpha$ & $1,98 \mathrm{a} \alpha$ \\
\hline & Média & $0,75 \mathrm{~B}$ & $3,23 \mathrm{~A}$ & $0,84 \mathrm{~A}$ & $1,84 \mathrm{~A}$ & $0,43 \mathrm{~A}$ & $1,63 \mathrm{~A}$ \\
\hline \multirow{8}{*}{ Atlantic } & $<30$ & 2,48 a $\beta$ & 3,25 a $\alpha$ & $0,84 \mathrm{a} \beta$ & 4,91 a $\alpha$ & - & - \\
\hline & $30-50$ & $0,88 \mathrm{~b} \alpha$ & 5,21 a $\alpha$ & $0,17 \mathrm{a} \alpha$ & $0,72 \mathrm{~b} \beta$ & 0,63 a $\alpha$ & 0,97 a $\alpha$ \\
\hline & $>50$ & - & - & $0,12 \mathrm{a} \alpha$ & $0,85 b \alpha$ & $0,35 \mathrm{~b} \alpha$ & $1,20 \mathrm{a} \alpha$ \\
\hline & Média & $1,68 \mathrm{~A}$ & $4,23 \mathrm{~A}$ & $0,37 \mathrm{~A}$ & $2,16 \mathrm{~A}$ & $0,49 \mathrm{~A}$ & $1,08 \mathrm{~B}$ \\
\hline & \multicolumn{7}{|c|}{ Cultivo de primavera } \\
\hline & & \multicolumn{6}{|c|}{ DAP } \\
\hline & & \multicolumn{2}{|c|}{70} & \multicolumn{2}{|c|}{76} & \multicolumn{2}{|c|}{99} \\
\hline & & $\begin{array}{l}\text { Açúcares } \\
\text { redutores }\end{array}$ & Sacarose & $\begin{array}{l}\text { Açúcares } \\
\text { redutores }\end{array}$ & Sacarose & $\begin{array}{l}\text { Açúcares } \\
\text { redutores }\end{array}$ & Sacarose \\
\hline \multirow{4}{*}{ Pérola } & $<30$ & $0,22 a \alpha$ & $1,23 a \alpha$ & $0,99 \mathrm{a} \alpha$ & 1,38 a $\alpha$ & - & - \\
\hline & $30-50$ & $0,24 \mathrm{a} \alpha$ & $1,70 \mathrm{a} \alpha$ & $0,26 \mathrm{~b} \alpha$ & 1,69 a $\alpha$ & $0,17 \mathrm{~b} \beta$ & $1,44 \mathrm{a} \alpha$ \\
\hline & $>50$ & - & - & $0,26 \mathrm{~b} \alpha$ & 1,66 a $\alpha$ & $0,37 \mathrm{a \alpha}$ & $1,21 \mathrm{a} \alpha$ \\
\hline & Média & $0,23 \mathrm{~A}$ & $1,46 \mathrm{~A}$ & $0,50 \mathrm{~A}$ & $1,60 \mathrm{~A}$ & $0,27 \mathrm{~A}$ & $1,33 \mathrm{~A}$ \\
\hline \multirow{4}{*}{ Atlantic } & $<30$ & $0,22 \mathrm{a} \alpha$ & $0,88 \mathrm{a} \alpha$ & $0,27 a \beta$ & 1,59 a $\alpha$ & - & - \\
\hline & $30-50$ & 0,20 a $\alpha$ & 1,48 a $\alpha$ & 0,23 a $\alpha$ & 1,03 a $\alpha$ & $0,32 \mathrm{a} \alpha$ & 1,95 a $\alpha$ \\
\hline & $>50$ & $0,22 \mathrm{a} \alpha$ & $1,93 \mathrm{a} \alpha$ & 0,18 a $\alpha$ & $0,83 \mathrm{a} \alpha$ & $0,17 \mathrm{a} \alpha$ & 0,73 a $\alpha$ \\
\hline & Média & $0,21 \mathrm{~A}$ & $1,43 \mathrm{~A}$ & $0,23 \mathrm{~B}$ & $1,15 \mathrm{~A}$ & $0,25 \mathrm{~A}$ & $1,34 \mathrm{~A}$ \\
\hline
\end{tabular}

(*) Médias seguidas por letras iguais não diferem entre si pelo teste de Tukey (5\%); letras minúsculas dentro da mesma cultivar (comparação entre tamanhos), letras maiúsculas para médias entre cultivares, legras gregas para comparação entre cultivares considerando o mesmo diâmetro e a mesma época.

ma das colheitas, porém pode ser destacada uma tendência de maiores teores de amido nos tubérculos da cultivar Atlantic aos 76 e 99 DAP. Em ambas cultivares houve redução no teor de amido ao final do ciclo, sendo que aos 70 DAP, os maiores teores foram observados nos tubérculos de maior diâmetro.

Para os teores de carboidratos solúveis totais (Tabela 1), considerando o fator cultivar, no cultivo de outono, foram verificados valores significativamente maiores para os tubérculos da cultivar Atlantic aos 53 DAP, sendo que aos 68 e aos 100 DAP ocorreu uma inversão, ou seja, maiores valores para os tubérculos da 'Pérola'. Verificou-se também uma redução nos teores de carboidratos solúveis totais para os tubérculos de ambas as cultivares ao final do ciclo de outono. A redução no teor de carboidratos solúveis totais na $\mathrm{cv}$. Atlantic ao longo do ciclo coincide com o aumento no teor de amido aos 68 DAP do cultivo de outono. Davies (1984) observou redução nos níveis de açúcares totais em tubérculos em desenvolvimento, indicando o aumento da taxa de síntese de amido. O mesmo foi relatado por Tjaden et al. (1998) indicando que níveis reduzidos de amido podem ser correlacionados com o aumento no conteúdo de açúcares solúveis.

Comparando cultivares, observou-se aos 53 DAP que os tubérculos de diâmetro menor que $30 \mathrm{~mm}$ da cultivar Atlantic apresentaram maior teor de carboidratos solúveis totais, enquanto na cv. Pérola os maiores teores de carboidratos solúveis totais foram verificados nos tubérculos maiores. Na segunda coleta (68 DAP), independente da cultivar, os tubérculos de diâmetro menor de $30 \mathrm{~mm}$ apresentaram maiores teores de carboidratos solúveis totais (Tabela 1). No cultivo de primavera, os tubérculos da cv. Pérola apresentaram maiores teores de carboidratos solúveis totais aos 76 DAP.

Os teores de açúcares redutores, expressos em termos de glicose (Tabela 2), foram significativamente maiores para os tubérculos da cultivar Atlantic ao 53 DAP, porém para os colhidos aos 100 DAP não diferiram entre as cultivares. Ao final do ciclo de outono, houve au- 
mento do teor de açúcares redutores nos tubérculos da cv. Atlantic, enquanto nos da cv. Perola ocorreu redução desses teores. Comparando as duas épocas de cultivo, verificou-se, independente da cultivar, maior teor de açúcares redutores durante o outono, o que é confirmado por Hertog (1997) que observou alta concentração de açúcares redutores em tubérculos colhidos em estação do ano de baixa temperatura.

O maior teor de carboidratos solúveis totais, açúcares redutores e sacarose verificado nos tubérculos menores, principalmente durante as primeiras coletas, indica o transporte de assimilados, via floema, até o órgão em desenvolvimento. Engels \& Marschner (1986) relatam que parâmetros da tuberização, como o transporte de fotoassimilados, influenciam a força do dreno dos tubérculos, indicando que o peso dos tubérculos é um fator que influencia o importe de fotoassimilados.

No cultivo de primavera, o maior teor de açúcares redutores é encontrado nos tubérculos da cv. Pérola, aos 76 DAP, sendo significativamente superior nos tubérculos de menor diâmetro. Melo (1999) relata que o teor de açúcares redutores diminui com a maturidade dos tubérculos, sendo o acúmulo de açúcares redutores uma característica genética, também influenciada por fatores ambientais. Isto explicaria a diferença entre as cultivares em relação ao teor de açúcares redutores, como também o maior teor de açúcares redutores nos tubérculos de menor diâmetro no cultivo de outono, visto que os teores de açúcares redutores são indicativos de imaturidade dos tubérculos. Entretanto, ao final do cultivo de primavera não houve diferença entre as cultivares em relação aos teores de açúcares redutores.

Os teores de sacarose nos tubérculos não diferiram entre as cultivares nas duas primeiras coletas, porém aos 100 DAP, os tubérculos da 'Pérola' apresentaram maiores teores de sacarose, sendo superior nos tubérculos com diâmetro maior de $50 \mathrm{~mm}$ (Tabela 2). Pode ser destacada a redução nos teores de sacarose ao final do ciclo de outono comparado à primeira coleta, em ambas cultivares. Analisando o fator tamanho dos tubérculos, diferenças significativas foram encontradas entre os tubérculos da cv. Atlantic aos 68 DAP, em que se destaca o maior teor de sacarose para os tubérculos menores de $30 \mathrm{~mm}$.

No cultivo de primavera, os teores de açúcares solúveis (carboidratos solúveis totais, açúcares redutores e sacarose) reduziram nos tubérculos da cv. Perola ao final do ciclo, acompanhando redução no teor de amido no mesmo período (Tabelas 1, e 2). Nos tubérculos da cv. Atlantic observou-se que os teores de carboidratos solúveis totais, açúcares redutores e sacarose aumentaram no final do ciclo, sendo mais evidente nos tubérculos com diâmetro entre 30-50 mm, apesar da redução no teor de amido no período. Isto talvez esteja relacionado ao estresse hídrico que ocorreu entre a segunda (76 DAP) e a última coleta (99 DAP).

Contudo, aos 76 e 99 DAP, maiores teores de sacarose foram observados nos tubérculos de menor diâmetro da cv. Atlantic, sugerindo o transporte de assimilados para os tubérculos em desenvolvimento. De acordo com Vos (1986) a cultura da batata é altamente sensível à seca e necessita de osmorregulação quando sujeita ao estresse hídrico. Altos níveis de sacarose podem manter as células osmoticamente ativas.

Deste modo, pode-se concluir que há redução no número de tubérculos e no teor de amido, em ambas cultivares, ao final dos dois ciclos de cultivo. Entretanto, a queda na produtividade de batata no cultivo de primavera foi influenciada pelo estresse hídrico do período, induzindo a um aumento no teor de açúcares solúveis na cv. Atlantic.

\section{LITERATURA CITADA}

AKAZAWA, T.; LIN, C-H.; LIN, J-H.; SMITH, N. Sucrose-starch transition in plant cells. In: PONTIS, H.G.; SALERMO, G.L.; ECHEVERRIA, E.J., eds. Sucrose metabolism, biochemistry, physiology and molecular biology, v. 14, Rockville: American Society of Plant Physiologists, 1995, p. 115-127.

APPELDOORN, N.J.G.; BRUIJN, S.M.; ROOTGRONSVELD, E.A.M.; VISSER, R.G.F.; VREUGDENHIL, D.; van der PLAS, L.H.W. Developmental changes of enzymes involved in conversion of sucrose to hexose-phosphate during early tuberisation of potato. Planta, v. 202, p. 220226, 1997.
BEUKEMA, H.P.; ZAAG, D.E. van der. Introduction to potato production. Wageningen: PUDOC, 1990. 208 p.

CHOUREY, P.S.; CHENG, W-H.; TALIERCIO, E.W.; IM, K.H. Genetic aspects of sucrosemetabolizing enzymes in developing maize seed. In: MADORE, A.M.; LUCAS, W.J. (eds.). Carbon partitioning and source-sink interactions in plants. Rockville: American Society of Plant Physiologists, 1995, p. 239-245.

CLEGG, K.M. The application of the anthrone reagent to the estimation of starch in cereals. Journal of Science Food Agricultural, v. 3, p. 4044, 1956.

DAVIES, H.V. Sugar metabolism in stolon tips of potato during early tuberisation. Zeitschrift Pflanzenphysiology. v. 113, p. 377-381, 1984.

DAVIES, H.V.; MACKAY, G.R. Exploitation of genetic variation to improve potato quality. Aspects of Applied Biology, v. 39, p. 45-49, 1994.

ENGELS, C.H.; MARSCHNER, H. Allocation of photosynthate to individual tubers of Solanum tuberosum L. III. Relationship between growth rate of individual tubers, tuber weight and stolon growth prior to tuber initiation. Journal of experimental botany, v. 37, n. 185, p. 1813-1822, 1986. FILGUEIRA, F.A.R. Novo manual de olericultura: agrotecnologia moderna na produção e comercialização de hortaliças. Viçosa: UFV, 2000. 402 p.

FREIRE, C.J.S. Estudos na área de fertilidade do solo na cultura da batata no âmbito da embrapa clima temperado. In: V Reunião Técnica Anual de Pesquisa e Extensão da Cultura da Batata da Região Sul do Brasil, 1998, Pelotas. Anais... Pelotas, RS, Documentos n. 46, 1998, p. 30-37. GUERIN, J.; CARBONERO, P. The spatial distribution of sucrose synthase isozymes in barley. Plant Physiology, v. 114, p. 55-62, 1997. HERTOG, M.L.A.T.M; TIJSKENS, P.S.; HAK, P.S. The effects of temperature and senescence on the accumulation of reducing sugars during storage of potato (Solanum tuberosum L.) tubers: A mathematical model. Postharvest biology and technology, v. 10, p. 67-79, 1997.

HODGE, J.E.; HOFREITER, B.T. Analysis and preparation of sugars. In: WHISTLER, R.L.; WOLFROM, M.L. (eds), Methods in carbohydrate chemistry, VI. Academic Press, New York, 1962. p. 356-378.

HUBER, S.C.; ISRAEL, D.W. Biochemical basis for partitioning of photosynthetically fixed carbon between starch and sucrose in soybean (Glycine max Merr.) leaves. Plant Physiology, v. 69, p. 691696, 1982.

KObMANN, J.; MÜLLER-RÖBER, B.; RIESMEIER, J.; FROMMER, W.B.; SONNEWALD, U.; WILLMITZER, L. Transgenic plants as a tool to analyzer carbohydrate metabolism. In: PONTIS, H.G.; SALERMO, G.L.; ECHEVERRIA, E.J., eds. Sucrose metabolism, biochemistry, physiology and molecular biology, v. 14, Rockville: American Society of Plant Physiologists, 1995, p. 100-106. McCREADY, R.M.; GUGGOLZ, J.; WENS, H.S. Determination of start and amylases in vegetables. Analytical Chemistry, v. 22, p. 1156-1158, 1950. MELO, P.E. Cultivares de batata potencialmente úteis para processamento na forma de fritura no Brasil e manejo para obtenção de tubérculos adequados. Informe Agropecuário, Belo Horizonte, v. 20, n. 197, p. 112-119, 1999. 
MILTHORPE, F.L.; MOORBY, J. The growth of the potato. Reprint of Proc. Third Triennial Conf. EAPR, p. 51-70, 1966.

NELSON, N.A. A photometric adaptation of the somogy method for the determination of glucose. Journal of Biology Chemistry, Baltimore, v. 153, p. 375-380, 1944.

PASSOS, S.M.G.; CANÉCHIO FILHO, V.; JOSÉ, A. Principais culturas. Instituto campineiro de ensino agrícola. Campinas-SP, v. 1, 1984. 427 p. PASSOS, L.P. Métodos analíticos e laboratoriais em fisiologia vegetal. EMBRAPA-CNPGL. Coronel Pacheco, 1996. 223 p.

PEREIRA, A.S. Composição química, valor nutricional e industrialização. In: REIFSCHNEIDER, F.J.B. coord. Produção de batata. Brasília: Linha gráfica e Editora, 1987. p.12-28.

PEREIRA, A.S.; COSTA, D.M. Qualidade e estabilidade de "chips" de batata. Horticultura Brasileira, Brasília, v. 15, n. 1., p. 62-65, 1997.
PEREIRA, A.S.; COSTA, D.M.; VENDRUSCULO, J.L.S.; DANIELS, J.; CHOER, E.; AUGUSTIN, E.; FORTES, G.R.L.; BERTONCINI, O.; HIRANO, E.; GOMES, C.B. BRS perola. Cultivar de batata adaptada a sistema de produção de pequenos produtores, para processamento de "batata palha". Agropecuária Clima Temperado, v. 3, n. 2, p. 287-290. 2000.

SALISBURY, F.B.; ROSS, C.W. Plant Physiology. $4^{\text {th }}$ ed. Wadsworth Publishing Company Belmont, California, 1992, $682 \mathrm{p}$.

SHALLENBERGER, R.S.; SMITH, O.; TREADWAY, R.H. Role of the sugars in the browning reaction in potato chips. Journal of Agriculture and Food Chemistry, v. 7, p. 274-277, 1959.

SILVA, A.C.F. Batata: alguns aspectos importantes. Agropecuária Catarinense, Florianópolis, v. 4, n. 4, p. 38-41, 1991.

TJADEN, J., MÖHLMANN, T.; KAMPFENKEL, K.; HENRICHS, G.;
NEUHAUS, H.E. Altered plastidic ATP/ADPtransporter activity influences potato (Solanum tuberosum L.) tuber morphology, yield and composition of tuber starch. The Plant Journal 16(5), p. 531-540, 1998.

TALBURT, W.F.; SMITH, O. Potato Processing. Third Edition. AVI Publishing Co., Westport, CT. 1975.

Van ES, A.; HARTMANS, K.M. Structure and chemical composition of the potato. In: RAASTOVSKI, A.; van ES, A. Storage of potatoes: post-harvest behaviour, store design, storage practice, handling. Pudoc Wageningen, 1987, p. 15-77.

VOS, J. Research on water relations and stomatal conductance in potatoes. 2. A comparison of three varieties differing in drought tolerance. In: BEEKMAN, A.G.B.; LOUWES, K.M.; DALLAERT, L.M.W.; NEELE, A.F.W. (Eds). Potato research of tomorrow. Pudoc, Wageningen, p. 29-35, 1986. 